\title{
SPYING ON NATURE
}

\author{
The biggest project in the history of ecology is nearing its dawn. Can its organizers \\ pull off the seemingly impossible and unite a disparate field behind its vision to \\ observe the ecosystems of the United States? Michael Hopkin reports.
}

\section{T}

hey call it the Hubble telescope of ecology. Like astronomy's best-known space telescope, the National Ecological Observatory Network (NEON) is planned to be big, expensive and able to see most of its universe. NEON, the biggest undertaking in the field's history, would blanket the United States with a network of observation stations - providing the most detailed picture ever of the state of its ecosystems.

But like the Hubble telescope, NEON and its organizers have faced a long and bumpy ride. They have fought off long-running charges that the project is too expensive, too inflexible and too poorly designed. Now they are hoping for the same sort of miraculous turnaround that the Hubble has experienced several times - to launch their project on time and with the full support of the ecology community.

Funding for NEON's construction remains at the discretion of Congress - the National Science Foundation (NSF) has requested $\$ 12$ million as part of its 2007 budget for building major research installations, rising to a total spend of $\$ 100$ million by 2011 . Other costs, such as operating and maintaining the project, are expected to more than double this figure.

\section{Grand challenge}

Meanwhile, the project's members have just finished presenting the latest version of the project's blueprint to a board of NSF officials. Should their plans meet with the approval of the board - who have experience in evaluating huge projects such as telescopes and particle accelerators - the team will proceed in making the preliminary design a reality.

According to the latest blueprint, NEON will involve setting up permanent measuring stations at locations in each of 20 'domains', which split the entire United States into zones representing every major climate and ecosystem type. Each location will boast an array of instruments, including a 10-metre tower to measure carbon dioxide flux, detect nitrogen oxides and record leaf wetness. The goal - the 'grand challenges' of ecology - is to assess how ecosystems respond to natural and humaninduced changes in climate, land use and the presence of invasive species.

It won't be easy. As the most expensive project in ecology's history, NEON has struggled for funding for years. Part of the problem is that it's difficult to put an overall price-tag on what is still a work in progress. "It's always in the hundred-million-dollar range," says Dan Johnson, communications director for NEON. "But it's frustrating because it's so hard to cost out." To make matters worse, early designs were poorly received by the community, and project organizers were accused of taking plans behind closed doors. Even now, some ecologists worry the project's vision still has not been clearly enough stated, despite having been on the drawing board for more than a decade.

The project was first dreamed up in the mid1990s by Jim MacMahon, now board chairman, and Bruce Hayden, an environmental scientist at the University of Virginia in Charlottesville. But it wasn't until 2003 that the NSF began to include NEON in its formal plans. Originally, NEON organizers pushed to have the system as standardized as possible, with identical hardware set up at some 60 locations. Each of the 20 domains was proposed to have three permanent research stations - one in a rural area, one in an urban one and a third in a transitional zone. But the design allowed very little scope for portable measuring equipment or flexibility to address local ecological issues on an ad hoc basis - such as the risk of wildfire in a region.

Chris Field, an ecologist at Stanford University in California, helped lead a team in writing NEON's latest blueprint to address such concerns. "If there was a consistent criticism, it was that earlier designs didn't present an inviting enough edifice to ecologists," he says.

Field also takes up the Hubble telescope analogy to explain why NEON needs local

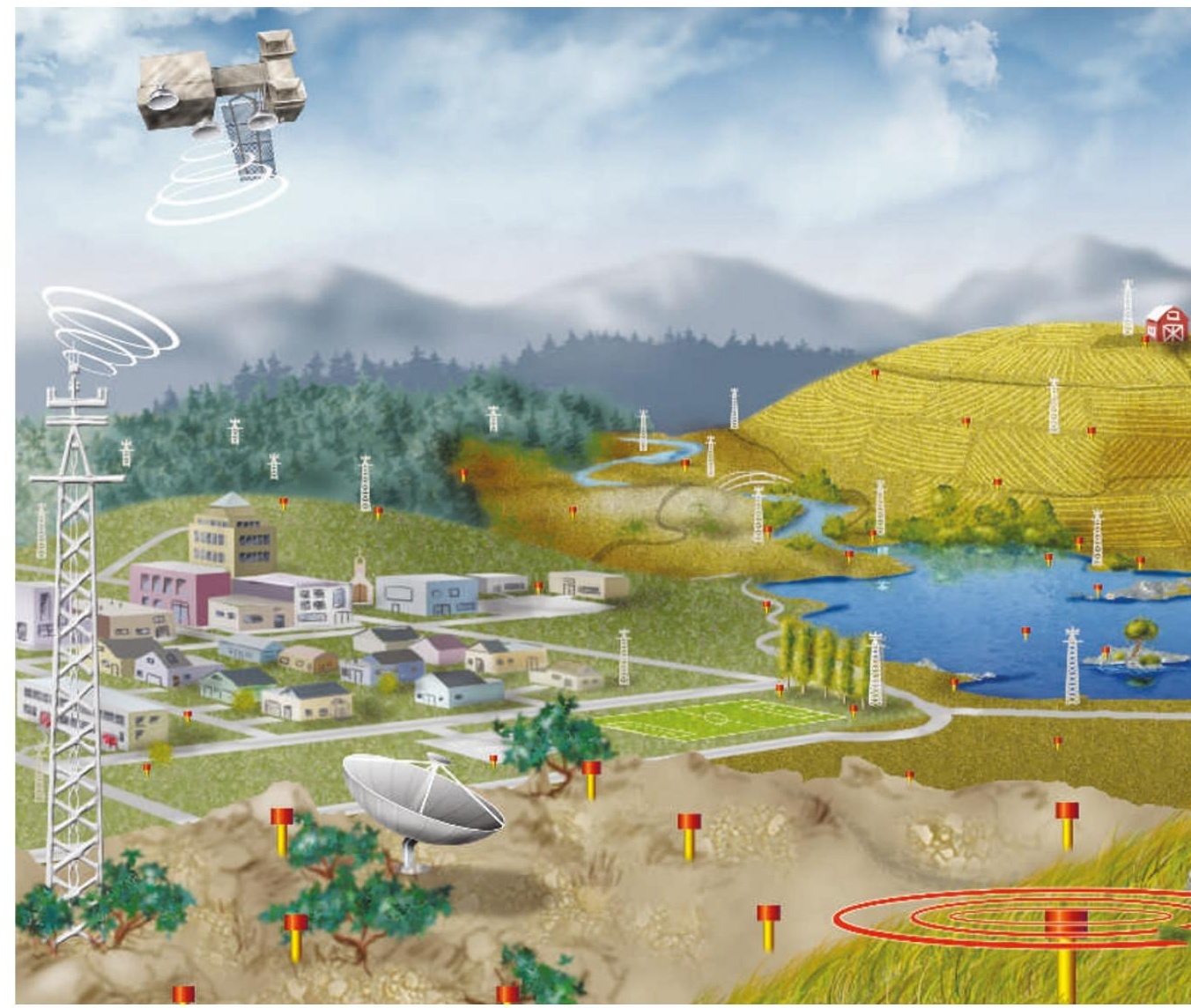


flexibility. "With a major telescope," he says, "you can improve flexibility by ensuring that it can point at different regions of the sky, or have different instruments built on." Similarly, ecologists want to be able to adapt their machinery to hit local hot spots of interest - such as a regional drought, or a flood such as that in New Orleans following Hurricane Katrina - with mobile measuring devices to improvise their studies.

\section{Progress report}

The latest blueprint seems to be soothing a lot of nerves and egos. In an open letter accompanying the document, MacMahon said that it is "gratifying to put to rest the gloom and doom that I have heard from some in the community". And until recently the worries and doubts were still very much at the surface. As recently as August, ecologists packed a conference room for a somewhat irritable 'village meeting' that updated NEON's progress. As one attendee put it: "Is this still going to attract money? Please tell me so I know how badly I'll sleep tonight!" But since the release of the latest blueprint, researchers in the main seem to be more determined to make the most of the new opportunities.

The new blueprint involves just a single 'core site' in each domain, located within a watershed area and ideally featuring a perennial river or stream. Each site will be equipped with a tower fully kitted out to measure gas fluxes, water vapour, solar irradiation, ozone concentrations, levels of pollen and bacteria, as well as air and soil temperature, wind speed and direction, precipitation and atmospheric pressure. Each site, which will take measurements from a few tens of square kilometres, will also feature terrestrial and aquatic sensors scattered over a wider area to measure temperatures and nutrient levels.

Apart from the core sites, NEON also includes a range of mobile instruments to measure specific local soil or aquatic processes; access to Earthobservation satellites and aircraft to monitor vegetation from above; and a 'land-use package' that will allow researchers to address issues such as the encroachment of new roads and agriculture into pristine land.

It's certainly a lot for ecologists to take on board. "I think the scientific community is generally supportive and encouraging," says ecologist David Briske of Texas A\&M University in College Station. "But the flip-side is that it's unprecedented and there's no model."

Hence the feelings of frustration, among some in the community, that the whole

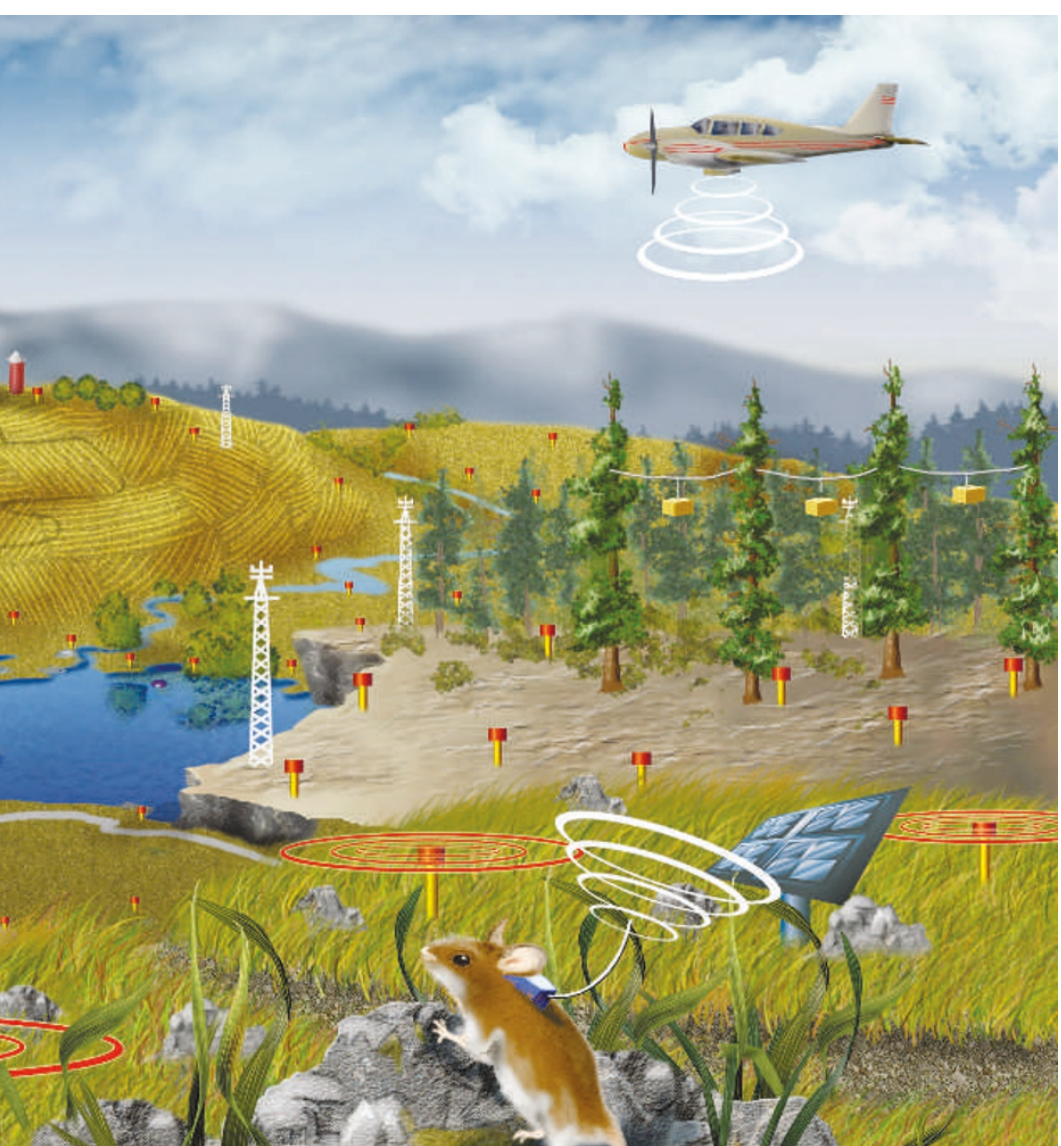

Nature watch: a network of stations will measure the impact of human activity and invasive species on ecosystems on a huge scale. endeavour may be getting too big for itself. Elizabeth Blood, one of NEON's organizers, tries to calm some of those fears. "We have never tried to do this before, to enrich biological science in this way," she says. "We are creating new ways of doing science - ways we can get only a glimpse of now."

In its new incarnation, NEON has the flexibility to address questions not yet dreamed of, says James Collins of the NSF, another member of the project team. "Projects can go for 10, 20, 30 years, but then after that people will be proposing new research," he says. "People who aren't even born yet will be developing new idiosyncracies for it."

Many ecologists are finally allowing themselves to become enthusiastic over NEON. Perhaps most tellingly, the leaders of the Consortium of Regional Ecological Observatories (COREO), a group set up to represent the ecologists who will use the infrastructure, now seem at peace with the NEON board. "Before, there was surprise and dismay at the inflexibility, and at the fact that there was little option for COREO members to comment. But most members are pleased with the re-review," says COREO chair Phil Robertson of Michigan State University in East Lansing.

\section{Lingering concerns}

Most concerns revolve around the ambition of the project's timeline: the system is planned to be up and running by 2013. NEON's public-relations team insists that the project is on schedule and, although Collins admits that this is a big task, he's confident it can be done. "It's ambitious, but the community has been involved in the research and development for years," he says. "The ideas have been proofed in concept - now we're at the point of knitting them together."

Although the grand-challenge questions are a useful guide, it is ultimately up to ecologists themselves to design the research that will be done. "The nuts and bolts are not in place yet," says Collins. "But these ecologists are the top investigators in their fields, so we want them to write the proposals."

So the debate about what questions the system will answer looks set to remain up in the air for a while to come. The NSF is currently in the process of a 'request for information' - consulting ecologists on the specific kinds of research they think they can perform with the new equipment. That process won't be complete for a few months. "Until the request for information comes out, all bets are off," says Robertson. America's ecologists aren't quite ready to breathe a sigh of relief yet.

Michael Hopkin writes for Nature from London. 